\title{
Exosomes derived from Hp-positive gastritis patients inhibit MCP-1 and MIP-1a expression in intestinal epithelial cells and improve DSS-induced colitis in mice
}

\section{Yufan Chen}

Children's Hospital of Fudan university https://orcid.org/0000-0002-4938-619X

Jie-Bin Huang

Department of Pediatrics, Ruijin Hospital, Shanghai Jiaotong University School of Medicine, 197 Ruijin Rd. II, Shanghai 200025,China

Hao Li

Department of Pediatric Neurosurgery, Children's Hospital of Fudan University, 399 Wan Yuan Road, Shanghai 201102, China

\section{Pu Li}

Department of Pediatrics, Ruijin Hospital, Shanghai Jiaotong University School of Medicine, 197 Ruijin Rd. II, Shanghai 200025,China

\section{Chun-Di Xu ( $\nabla$ chundixu55@163.com )}

Department of Pediatrics, Ruijin Hospital, Shanghai Jiaotong University School of Medicine, 197 Ruijin Rd. II, Shanghai 200025,China. Department of Pediatrics, Ruijin Hospital north, Shanghai Jiaotong University School of Medicine, 999 Xiwang Rd, Shanghai

\section{Research}

Keywords: Exosome, Hp, IBD, NLRP12, Notch pathway

Posted Date: May 13th, 2020

DOI: https://doi.org/10.21203/rs.3.rs-28075/v1

License: (c) (1) This work is licensed under a Creative Commons Attribution 4.0 International License. Read Full License 


\section{Abstract}

Background: Previous studies have suggested that Helicobacter pylori (H. pylori, Hp) infection has a protective function in inflammatory bowel disease (IBD); Exosomes (Exo) are novel cell-cell communication mediators and their association with inflammatory immune responses has received great attention. however the mechanisms regarding the role of exosomes between $\mathrm{Hp}$ infection and IBD are limited.

Methods: Human intestinal epithelial cells were treated with serum exosomes derived from Hp-positive chronic gastritis patients (Exo(Hp)), the expression of cytokines, inflammasome and signal pathway genes were detected by antibody microarray or PCR array. Furthermore, DSS-induced colitis mice were treated with exosomes by intraperitoneally injection to study the effect of Exo(Hp) in IBD.

Results: Serum exosomes derived from Hp-positive chronic gastritis patients promoted NLRP12 expression in intestinal epithelial cells, and NLRP12 decreased chemokine MCP-1 and MIP-1a expression by inhibiting the Notch signaling pathway. In vivo, Exo(Hp) could attenuated inflammatory responses in DSS-induced colitis and improved colitis symptoms, which was associated with the increase in NLRP12 expression. Furthermore, the immunohistochemistry results showed that NLRP12 was negatively correlated with the disease activity of pediatric IBD patients.

Conclusions: Exo(Hp) inhibited the Notch signaling pathway through the promotion of NLRP12 expression to further down-regulate MCP-1 and MIP-1 a expression in intestinal epithelial cells and thereby attenuate DSS-induced colitis in mice. These results provide new theoretical bases for further elucidation of the intestinal protection mechanisms of Hp infection in IBD, and provide new targets for explorations of effective interventional strategies for IBD.

\section{Background}

Since Marshall and Warren successfully cultured Helicobacter pylori (H. pylori, Hp) from gastric mucosal tissues in 1983, Hp infection and pathogenesis have received great attention(1). More than one-half of the global population is estimated to be infected with $\mathrm{Hp}(2)$. Current studies have confirmed that $\mathrm{Hp}$ is closely associated with the development of gastritis, peptic ulcer, mucosa-associated lymphoid tissue (MALT) lymphoma and even gastric cancer and is an important factor that causes extragastric diseases, including cardio-cerebrovascular, blood system, respiratory system, intestinal and autoimmune diseases $(3,4)$. El-Omar et al published the first paper on the correlation between $\mathrm{Hp}$ and inflammatory bowel disease (IBD) in 1994. Their study showed that the Hp antibody positive rate in IBD patients was only $22 \%$, which was significantly lower than the rate in the control group (52\%)(5).

Based on the conclusion of el-Omar et al, many scholars have performed studies to validate the association between $\mathrm{Hp}$ infection and IBD; however, the conclusions were not completely consistent. There are 3 groups of conclusions: Hp infection is negatively correlated with IBD; there is no correlation between these two conditions; and $\mathrm{Hp}$ is a pathogenic factor of IBD. However, the majority of the studies 
supported the hypothesis that $\mathrm{Hp}$ infection has a protective function in the development and progression of IBD(6). Many studies have attributed the negative correlation between IBD and Hp infection to two possibilities: drug factors and regulation of the host immune system by Hp. For example, the commonly used sulfasalazine, 5-aminosalicylic acid and antibiotics are thought to be associated with a lower rate of $\mathrm{Hp}$ infection $(7,8)$. Currently, the majority of studies consider that the reason for the lower Hp infection rate in IBD patients is mainly associated with regulation of the host immune system by Hp. However, the specific mechanisms are not clear.

After antigen stimulation, gastrointestinal epithelial cells can express a series of pattern recognition receptors (PRRs) and release cytokines that contribute to the regulation of adaptive immunity.

Researchers have shown that gastrointestinal epithelial cells can also secrete exosomes that carry a large amount of proteins, lipids, and nucleic acids (9). These exosomes link different cell types in the intestinal system to play a role in cell-cell communication and participate in immune regulation, such as the regulation of the intestinal flora balance(10). Exosomes derived from various sources play important roles in the maintenance of gastrointestinal tissue homeostasis and the development and progression of various intestinal diseases though cell-cell communication. For example, some studies have shown that exosomes secreted by human umbilical cord mesenchymal stem cells (hucMSCs) can attenuate the inflammatory responses in dextran sulfate sodium salt (DSS)-induced colitis model animals (11). Recently, the relationship between the inflammatory responses induced by $\mathrm{Hp}$ and exosomes has also received attention. Wang et al showed that macrophages secreted exosomes after Hp infection; in addition, microRNA-155 carried by exosomes promoted the secretion of TNF-a, IL-6, and IL-23; inhibited the expression of CD40, CD63, CD81, and MCH-l; and inhibited the MyD88 and NF-KB inflammatory signaling pathways to mediate the $\mathrm{Hp}$ infection-induced inflammatory responses by macrophages(12). Another study indicated that plasma-derived and gastric epithelial cell-derived exosomes carry $\mathrm{Hp}$ virulence factor cytotoxin-associated gene A (CagA) and enter the blood circulation. These exosomes may be transported to organs and tissues to participate in the pathogenesis of Hp-induced extragastric diseases (13).

In this study, we aimed to investigate the immune regulatory functions of exosomes derived from the serum of Hp-infected patients on intestinal epithelial cells and the effect of exosome intervention on IBD. We also explored the intestinal protection function of $\mathrm{Hp}$ infection in IBD in the context of exosomes to provide new theoretical bases for further elucidation of the immune regulatory mechanisms of intestinal mucosal injury in IBD and new directions and targets for explorations of effective interventional strategies for IBD.

\section{Methods}

\section{Patients and tissue specimens}

A total of 28 children patients with active IBD who were recruited randomly from the Department of Pediatrics at Ruijin Hospital and Ruijin Hospital North between March 2016 and May 2017. The children 
included 19 males and 9 females with ages between 1 and 16 years (mean age $8.3 \pm 3.25$ years). There were 14 cases of ulcerative colitis and 14 cases of Crohn's disease. The diagnosis of IBD was confirmed by 3 physicians on the basis of clinical assessments, endoscopy, pathology, and serology; in addition, the diagnosis was not changed after at least 6 months of follow-up. One block of involved intestinal tissues was collected from each patient during the endoscopic biopsy. Four children who had abdominal pain symptoms but did not have obvious inflammatory changes in the endoscopic and pathological examinations were used as the normal control group, and their intestinal mucosal biopsy tissues were collected. In addition, whole blood specimens were collected from $5 \mathrm{Hp}$-positive pediatric patients with chronic gastritis confirmed by our department (confirmed by the ${ }^{13} \mathrm{C}$ breath tests, endoscopic examination, and pathology and without other diseases) and 3 healthy volunteers. The detailed features of gastritis patients and healthy volunteers chosen for exosome extraction are presented in Table 1.The blood samples were centrifuged at $3000 \times \mathrm{g}$ for $10 \mathrm{~min}$ to obtain serum samples and then were stored at $-80^{\circ} \mathrm{C}$.

\section{Correlation analyses between NLRP12 expression and disease activity}

The disease activity of the 28 IBD pediatric patients was evaluated. The Crohn's disease scoring system referenced the Pediatric Crohn's Disease Activity Index (PCDAl) to score the disease history, laboratory results, changes in body height, and physical examination(14). The reference standard for ulcerative colitis was the Pediatric Ulcerative Colitis Activity Index (PUCAI), and the disease activity scoring was performed based on abdominal pain and stool properties and frequencies (15). The correlation between NLRP12 expression in the intestinal mucosa and the disease activity of IBD pediatric patients was analyzed.

\section{Immunohistochemical detection of NLRP12 expression in intestinal mucosal tissues}

The detection procedure was performed using a streptavidin-peroxidase (SP) reagent kit according to the manufacturer's instructions. The NLRP12 antibody was purchased from Sigma-Aldrich. Result determination: NLRP12-positive cells showed a yellow-brown color in the intestinal epithelial cells or cytoplasm. The blind method was adopted. Five high-power fields in each section were selected under a light microscope to count the percentages of positive cells in each field. The average value was calculated. The classification was performed according to the staining intensity and the number of positive cells. Scoring according to the staining intensity was performed as follows: a light color slightly higher than the background color was 1 point, moderate staining that was significantly higher than the background color was 2 points, and strong staining that was close to a brown color was 3 points. Scoring according to the number of positive cells was performed as follows: a positive cell proportion $<10 \%$ was 0 points, $10 \%-30 \%$ was 1 point, $31 \%-50 \%$ was 2 points, $51 \%-75 \%$ was 3 points, and $>75 \%$ was 4 points. A score $>4$ points obtained via multiplication between these two scores indicated that the patient had positive expression.

\section{Extraction and identification of exosomes}


Serum exosomes were extracted using the ExoQuickTM reagent kit (SBI, Palo Alto, CA, USA). The manipulation was performed according to the reagent kit manual. Briefly, $200 \mu \mathrm{l}$ of serum was mixed with $50 \mu \mathrm{l}$ of ExoQuick solution and incubated at $4^{\circ} \mathrm{C}$ overnight. The mixtures were centrifuged at $10000 \mathrm{~g}$ for $30 \mathrm{~min}$ at $4^{\circ} \mathrm{C}$, and the exosome pellets were resuspended in diluent $\mathrm{C}$ (Sigma), resuspended in phosphate-buffered saline (PBS), or lysed immediately for the next experiment. Particle size was measured using a NanoSight LM10 HS-BF instrument (NanoSight Ltd, Salisbury, UK) on the basis of nanoparticle-tracking analysis (NTA). Briefly, exosome pellets resuspended in PBS were diluted to a concentration of $3 \mu \mathrm{g} / \mu \mathrm{L}$ after protein quantification, and then, the exosome suspensions were further diluted 100 -fold and analyzed following the manufacturer's protocol. Transmission electron microscopy (TEM) was performed to detect exosome morphology. Briefly, exosomes suspended in $2 \%$ glutaraldehyde were loaded on a copper grid and negatively stained with $3 \%(\mathrm{w} / \mathrm{v})$ aqueous phosphotungstic acid for 1 min. The grid was then examined using an FEI Tecnai G2 Sprit Twin transmission electron microscope (JEM-1230; Jeol Ltd., Tokyo, Japan). The surface protein markers of exosomes, including CD63 and TSG101, were detected using western blotting. The obtained exosomes were named Exo(Con) and Exo(Hp) to present serum-derived exosomes from healthy volunteers and $\mathrm{Hp}$-positive pediatric patients with chronic gastritis, respectively.

\section{Cell culture}

The human intestinal epithelial cell line NCM460 was purchased from INCELL (USA) and cultured in McCoy's $5 \mathrm{~A}$ culture medium containing $10 \%$ fetal bovine serum (FBS), $100 \mathrm{mg} / \mathrm{mL}$ penicillin, and 50 $\mu \mathrm{g} / \mathrm{mL}$ streptomycin (Gibco, USA) in a $37^{\circ} \mathrm{C}$ and $5 \% \mathrm{CO}_{2}$ cell incubator. The culture medium was replaced with fresh culture medium every 2-3 days. Cells at the logarithmic growth phase were collected, and exosomes were added based on the requirements of the experiment. After siRNA transfection (siRNAs targeting NLRP12 were constructed and synthesized by Genomeditech Shanghai, and transfected into cells using Lipofectamine 2000) and DAPT (N-[N-(3,5-difluorophenacetyl)-1-alanyl]-S-phenylglycine t-butyl ester) (Sigma-Aldrich, USA) stimulation, the cells were collected for detection.

\section{Western blotting}

NCM460 cell and exosome protein samples were obtained using RIPA lysis buffer. The concentrations of samples were determined using the bicinchoninic acid (BCA) method. Polyacrylamide gels were prepared, and samples were separated using electrophoresis. Proteins were transferred onto a membrane and blocked. The primary antibody was added and incubated at $4^{\circ} \mathrm{C}$ overnight. Then, the membrane was incubated with the secondary antibody at room temperature for $1 \mathrm{~h}$. The blots were exposed to X-ray films and photographed. The grey density value of the target band was analyzed using the Image $\mathrm{J}$ system to reflect the protein expression level. The experiment was repeated 3 times. The following primary antibodies were used: NLRP12 (1:1000, Sigma-Aldrich, USA), anti-CD63 (1:1000, Abcam, USA), TSG101 (1:1000, Abcam, USA), calnexin (1:1000, Sigma-Aldrich, USA), GADPH (1:1000, Sangon Biotech, China), NLRP3 (1:1000, Sigma-Aldrich, USA), pro-caspase-1 (1:1000, Abcam, USA), Notch1 (anti-Notch1 
intracellular domain, NICD,1:1000, Abcam, USA), HES-1 (1:500, OriGene Technologies, USA), HES-5 (1:1000, Abcam, USA), HEY-1 (1:1000, Proteintech Group, USA), and MCP-1 (1:1000, Abcam, USA).

\section{Real-time quantitative PCR (qRT-PCR)}

Total RNA was extracted from the NCM460 cells and mouse colon tissues using TRIzol (Invitrogen). The extracted total RNA $(2 \mu \mathrm{g})$ was reverse transcribed into cDNA using a PrimeScript RT MasterMix reagent kit (TaKaRa). Next, qRT-PCR was performed using a SYBR Green Supermix reagent kit (TaKaRa) in a LightCycler 480 system (Roche). The $\mathrm{Ct}$ value was obtained from the PCR reaction curve to calculate the relative expression level. GADPH was used as the internal control. $\triangle \mathrm{Ct}$ was the difference in expression between the target gene and the internal control gene. The expression levels of the genes were expressed using $2^{-\Delta C t}$. All experiments were repeated at least 3 times. The primer sequences are shown in Table 2 .

\section{Enzyme-linked immunosorbent assay (ELISA)}

The cell culture supernatant was collected from NCM460 cells transfected with the NLRP12 siRNA. The IL-1 $\beta$ secretion level was detected using an ELISA kit(Anogen, Missassauga, ON,Canada), and fecal Lipocalin-2 (LCN-2) levels were also quantified using mouse Lipocalin-2 ELISA kit (R\&D Systems, Minneapolis, MN) according to the manufacturer's instructions. After dilution of the standards and the sample loading, incubation, and washing steps, the absorbance value of each well was measured at a wavelength of $450 \mathrm{~nm}$ using a Softmax Pro 5 microplate reader. In addition, one blank control was used.

\section{Establishment of a colitis model and exosome intervention}

A dextran sulfate sodium salt (DSS, molecular mass 36-50 kDa, MP Biomedicals, France)-induced mouse colitis model was established. All mice were normally housed for 1 week before the experiments to observe changes in eating, drinking, activities, and body weight. A total of $28 \mathrm{C} 57 \mathrm{BL} / 6$ mice were randomly divided into 4 groups ( $n=7$ mice/group) as follows: normal control group (Con group), model group (DSS group), Exo(Con) intervention group (DSS+Exo(Con) group), and Exo(Hp) intervention group (DSS+Exo(Hp) group). For $9 \mathrm{~d}$, the control group received normal saline for drinking and the model group received a $5 \%$ DSS solution for drinking. Based on their consumption of the $5 \%$ DSS solution, the intervention group received an intraperitoneal injection of exosomes $(50 \mu \mathrm{g} / \mathrm{animal})$ at model establishment and every $24 \mathrm{~h}$. During model establishment, changes in body weight, stool properties, and blood in the stools of the mice were observed every day. Disease activity index (DAl) scoring was performed based on the above indicators. For fecal sample collection, mice were placed in clean polycarbonate cages without bedding until they defecated.Fecal samples were reconstituted in PBS containing $0.1 \%$ Tween 20 at a concentration of $100 \mathrm{mg}$ feces/ $\mathrm{ml}$ and vortexed for $30 \mathrm{~min}$ to yield a homogenous suspension. Mice were sacrificed $9 \mathrm{~d}$ after model establishment. The mouse colons and spleens were collected to evaluate the colon lengths and spleen sizes. Colon tissues at approximately 2 $\mathrm{cm}$ from the ileocecum were isolated and fixed in $4 \%$ formalin for histopathological examinations and scoring. In addition, some tissues were cryopreserved at $-80^{\circ} \mathrm{C}$ for subsequent RNA extraction and qRTPCR detection. 


\section{Detection of changes in the expression of inflammasome-associated genes, signaling pathways, and inflammatory cytokines using PCR array and antibody array technology}

After exosome intervention in NCM460 cells for $24 \mathrm{~h}$, cell supernatants and cell samples were collected. Total RNA was extracted from the cell samples using TRIzol and reverse transcribed into cDNA. Changes in inflammasome-associated genes and signaling pathways were detected using PCR array technology. The PCR ARRAY of Human Inflammasomes and the Human Signal Transduction Pathway Finder PCR Array were purchased from BioTNT (Shanghai, China). In addition, changes in inflammatory cytokines in the cell supernatants were detected using inflammatory cytokine antibody array technology. The Human Inflammation Array was purchased from Raybiotech.

\section{Statistical analyses}

Measurement data are all expressed as the mean \pm SEM. Data input and plotting were performed using GraphPad Prism 5.0 or EXCEL 2007. The statistical significance of the differences was calculated by performing Student's t-test or one-way analysis of variance (anova). The enumeration data were evaluated by performing $\chi 2$ test or Fisher's exact test as appropriate. $P<0.05$ was the standard for the statistical examinations. $\mathrm{P}<0.05$ indicates significant differences, and $\mathrm{P}>0.05$ indicates without significant differences.

\section{Results}

\section{Isolation and identification of serum-derived exosomes}

The detection of exosomes using electron microscopy is intuitive and reliable. Electron microscopy can be used not only to observe exosome structures but also to measure exosome size. In addition, it can be used to roughly estimate exosome purity. Therefore, this method is preferred for the identification of exosomes. Based on electron microscopy, the extracted exosomes showed a round or oval vesicular structure and were of homogeneous size. The smaller structures might have been caused by the influence of cryopreservation on the exosomes. These results basically conformed to the morphological features of exosomes. The electron microscopy analysis also showed that the exosomes could adopt a scattered distribution or be clustered into groups (Fig. 1a). Exosome surface-specific molecules include CD63, TSG101, CD81, CD9, and Hsc70. These molecules are highly conserved proteins and have been extensively applied for the specific labeling of exosomes. Calnexin is an integral protein derived from the endoplasmic reticulum (ER) and is not expressed in exosomes. The western blotting results showed that the exosomes expressed CD63 and TSG101 but did not express calnexin (Fig. 1b). The nanoparticletracking analysis of the exosome preparations was performed by a NanoSight system, and a peak was observed at approximately $100 \mathrm{~nm}$ (Fig. 1c). Combined, these results indicated that the extracted vesicular particles were exosomes.

Promotion of NLRP12 expression in intestinal epithelial cells by serum exosomes from Hp-positive patients with chronic gastritis 
The relationship between exosomes and inflammasomes has been confirmed by some studies; for example, inflammasome signaling pathways affect the composition of the components carried by exosomes (16). Studies have also confirmed that exosomes can directly activate or inhibit inflammasome signaling pathways $(17,18)$. Therefore, the influence of serum-derived exosomes from $\mathrm{Hp}$-positive patients on the regulation of inflammasome expression in intestinal epithelial cells was investigated. NCM460 intestinal epithelial cells were stimulated by the extracted exosomes $(100 \mu \mathrm{g} / \mathrm{mL})$ for $24 \mathrm{~h}$, and total RNA was extracted. The PCR array showed that Exo(Hp) increased NLRP12 and NAIP mRNA expression and decreased NLRP3 and NLRP5 mRNA expression. The change in NLRP12 expression was the most evident response, showing an increase greater than 5 -fold (Table 3 and Fig. 1d). Therefore, subsequent experiments were focused on NLRP12. The change in the NLRP12 protein level was validated using western blotting. The results showed that NLRP12 expression gradually increased with increased Exo(Hp) $(100 \mu \mathrm{g} / \mathrm{mL})$ treatment time (Fig. 1e). Because the NLRP12 inflammasome signaling pathways were closely associated with NLRP3 (19), western blotting was performed. The results showed that Exo(Hp) did not affect the NLRP3 protein expression level, although it did decrease the mRNA expression level (Fig. 1f).

\section{Specific inhibition of MCP-1 and MIP-1a expression by Exo(Hp)-induced NLRP12 expression}

To explore the regulation of intestinal epithelial inflammatory cytokine expression by exosomes, NCM460 cells were treated with Exo(Hp) $(100 \mu \mathrm{g} / \mathrm{mL})$ for $24 \mathrm{~h}$, and the cell supernatant was collected for the inflammatory cytokine antibody array. The results showed that Exo( $\mathrm{Hp})$ upregulated the ICAM-1, IL-1 a, IL6R, PDGF-BB, and RANTES levels by more than 1.5 -fold $(p<0.05)$ and downregulated the IL-2, IL-4, TNF-a, MCP-1, and MIP-1a levels by more than 1.5 -fold $(p<0.05)$ (Fig. 2a). To validate whether changes in these inflammatory cytokines were associated with NLRP12, interference with NLRP12 expression was performed using siRNA technology. The Exo(Hp) intervention and mRNA changes in the abovementioned inflammatory cytokines were determined using qRT-PCR, and the results showed that 5 inflammatory cytokines that were upregulated by $\operatorname{Exo}(\mathrm{Hp})$ induction were not downregulated upon NLRP12 expression interference. These results indicated that the upregulation of these cytokines was not associated with NLRP12 expression. In addition, among the 5 inflammatory cytokines that were downregulated by Exo(Hp) induction, only MCP-1 and MIP-1a had increased expression levels upon NLRP12 expression interference (Fig. 2b). These results indicated that Exo(Hp)-induced NLRP12 expression specifically inhibited MCP-1 and MIP-1 a expression in intestinal epithelial cells. NLRP12 can bind to apoptosisassociated speck-like protein (ASC) to form the NLRP12 inflammasome and activate caspase-1 to promote the expression of downstream inflammatory cytokines, such as IL-1 $\beta$. This function is associated with the NLRP3 inflammasome $(19,20)$ and can directly influence cytokine expression independent of inflammasomes, having either a promoting or inhibitory effect (21). Therefore, western blotting was performed to validate whether the function of NLRP12 in the inhibition of MCP-1 and MIP-1a expression was inflammasome-dependent. The results showed that caspase-1 activation was not affected by the interference to NLRP12 expression (Fig. 2c). The ELISA results also showed that the IL-1 $\beta$ expression level did not change (Fig. 2d). Our previous results showed that Exo(Hp) did not affect NLRP3 
expression. Taken together, these results showed that the inhibition of MCP-1 and MIP-1a expression by NLRP12 was independent of inflammasomes.

\section{Inhibition of the Notch signaling pathway by Exo(Hp)}

Exo(Hp) inhibited MCP-1 and MIP-1a expression. To validate the signaling pathways involved in this inhibition, intestinal epithelial cells were treated with Exo(Hp) $(100 \mu \mathrm{g} / \mathrm{mL})$ for $24 \mathrm{~h}$, and cellular total RNA was extracted for a PCR array of signaling pathway genes. The results showed that the expression levels of Notch signaling pathway-associated receptors, ligands, and downstream target genes, such as the Notch1, Hes1, Hes5, Hey1, Hey2, ID1, Jagged1, and LFNG genes, were all decreased (Fig. 3a).

Furthermore, changes in the NICD protein level were detected using western blotting. The results showed that, with the increase in the Exo( $\mathrm{Hp})$ stimulation time, NICD expression was gradually decreased and reached its lowest level at $48 \mathrm{~h}$ (Fig. $3 \mathrm{~b})$. These results indicated that Exo(Hp) inhibited the Notch signaling pathway in intestinal epithelial cells.

\section{Inhibition of MCP-1 and MIP-1a expression by NLRP12 through inhibition of the Notch signaling pathway}

The Notch signaling pathway plays important roles in immune inflammatory responses, including regulation of immune cell differentiation, proliferation, and activation (22) and involvement in the regulation of inflammatory immune responses and inflammatory cytokine expression, and it is closely associated with various inflammation-related diseases $(23,24)$. Based on this knowledge and combined with the above study results, we hypothesized that inhibition of MCP-1 and MIP-1a expression by NLRP12 might be associated with the Notch signaling pathway. To validate this supposition, interference of NLRP12 expression was performed by siRNA (Fig. 4a). The western blotting results showed that the NICD, Hes1, Hes5, and Hey1 protein expression levels increased significantly after NLRP12 interference (Fig. 4b). The qRT-PCR results showed that the Notch1, Jagged-1, Hes-1 and Hes 5 expression levels were significantly increased (Fig. 4c). These results suggested that NLRP12 inhibited the Notch signaling pathway. To further validate whether the Notch signaling pathway affected the regulation of MCP-1 and MIP-1a expression through NLRP12, the Notch signaling pathway inhibitor DAPT was used as an interventional measure. Combined, the results obtained wit NLRP12-siRNA interference technology showed that interference with NLRP12 in Exo(Hp)-treated NCM460 cells increased MCP-1 and MIP-1a expression and that this function was inhibited by DAPT (Fig. 4d-g). All of these results indirectly indicated that NLRP12 inhibited MCP-1 and MIP-1 a expression by inhibiting the Notch signaling pathway.

\section{Attenuation of DSS-induced colitis in mice by Exo(Hp)}

Previous findings demonstrated that NLRP12 was closely associated with IBD. NLRP12 has been shown to reduce inflammatory responses in mouse colitis and inhibit the development of colitis-induced tumors. In NLRP12 gene-knockout mice, colitis was more easily induced, the release of cytokines and chemokines was increased, and the risk of metaplasia and carcinogenesis of intestinal epithelial cells was increased $(25,26)$. In summary, NLRP12 has protective functions in colitis. On the basis of these findings, we used DSS to establish a mouse colitis model. Exosomes (50 $\mathrm{\mu g} / \mathrm{animal})$ were intraperitoneally injected upon 
model establishment and every $24 \mathrm{~h}$ to investigate the function of Exo(Hp) in mice with colitis. The results showed that the DAl of the mice with colitis that received intraperitoneal injections of Exo(Hp) was significantly improved compared to that of the DSS and Exo(Con) group mice; in addition, the reduction in body weight caused by colitis was obviously attenuated (Fig. 5a). The colon lengths were longer in the mice in the $\operatorname{Exo}(\mathrm{Hp})$ intervention group than they were in the DSS or Exo(Con) intervention groups (Fig. $5 b$ ), whereas the spleen sizes were decreased compared to those in the 2 control groups (Fig. 5c). These results suggested that Exo(Hp) improved DSS-induced colitis in mice. The histopathological examination showed that the destruction of the mucosal structure of the colon and inflammatory cell infiltration was significantly attenuated in the mice in the Exo( $\mathrm{Hp})$ intervention group and that the destruction of the splenic structures in the mice was also improved (Fig. 5d). The histopathological scoring results showed that the scores of the mice in the Exo(Hp) intervention group were lower than those in the DSS and Exo(Con) groups (Fig. 5e). Proinflammatory cytokine and immunoregulatory cytokine expression in the colons of the mice with acute DSS-induced colitis was determined by real-time PCR. The TNF- $a$, IFN- $y$, IL$1 \beta$ and IL-10 mRNA levels were decreased in the mice in the Exo( $\mathrm{Hp})$ intervention group compared to those in the DSS and Exo(Con) intervention groups. Moreover, changes in fecal LCN-2 levels were detected by ELISA and showed the same trend (Fig. 5f). These results suggested that Exo(Hp) attenuated the DSS-induced inflammatory destruction of the colonic mucosa. As described above, NLRP12 had a protective function in colitis, and Exo( $\mathrm{Hp})$ promoted NLRP12 expression; therefore, we speculated that the function of $\operatorname{Exo}(\mathrm{Hp})$ in the attenuation of DSS-induced colitis in the mice might be associated with NLRP12. We extracted RNA from mucosal tissues of the mouse colons in all the groups for qRT-PCR analysis. The results showed that NLRP12 expression was significantly decreased in the mice in the DSS group compared to that in the normal control group. The level did not change after Exo(Con) intervention, whereas the NLRP12 level significantly increased and was accompanied by a decrease in MCP-1 and MIP-1 a expression after the Exo(Hp) intervention (Fig. $5 \mathrm{~g}$ ). These results suggested that the function of $\operatorname{Exo}(\mathrm{Hp})$ in the attenuation of DSS-induced colitis in mice was closely associated with the increase in NLRP12 expression.

\section{The negative correlation between NLRP12 expression and disease activity in pediatric IBD patients}

To validate the function of NLRP12 in human IBD, diseased intestinal mucosal tissues were collected from pediatric patients with active IBD to analyze NLRP12 expression using immunohistochemistry. Positive NLRP12 staining was observed in $64.3 \%$ (9 of 14) of UC patients, $42.9 \%$ (6 of 14) of the CD patients and $100 \%$ (4 of 4 ) of the normal controls (Fig. 6a). Moreover, the results showed that, regardless of whether the patients had UC or CD, the disease activity of the IBD pediatric patients with positive NLRP12 expression was decreased compared to that in the patients with negative NLRP12 expression (Fig. 6b). These results were consistent with those obtained from the IBD mouse model and suggested that NLRP12 has a function in the inhibition of colitis.

\section{Discussion}


Recent studies have shown that, in addition to PRRs and cytokines involved in cell-cell communication, extracellular vesicles (EVs) play an important role in cell-cell communication as novel secretory mediators(27). Exosomes are EVs secreted by various types of cells and have a diameter of approximately 50-150 nm. They appear to have globular or goblet shapes under an electron microscope and are derived from multivesicular bodies (MVBs) in the endocytosis pathway. MVBs fuse to the cell membrane in a calcium-dependent manner in cells and release multiple internal membranous vesicle structures into the extracellular matrix to form exosomes $(28,29)$. Raposo et al first discovered that EVs could activate adaptive immunity in 1996 (30); since this discovery, EVs have received attention from researchers in the field of immunology.

Exosomes and EVs are rich in substances from the mother cell components. They play important roles in cell-cell communication by transferring proteins, lipids, and nucleic acids. EVs are present in most body fluids. Increasing evidence has confirmed that EVs play not only important roles in the regulation of normal physiological processes, such as tissue repair, stem cell maintenance, immune surveillance, and blood coagulation, but also in the pathophysiological processes of many diseases(31). EVs exert their functions in many ways, including direct activation of cell surface receptors through membrane surface proteins and bioactive lipid ligands, fusion with the plasma membrane of recipient cells through membrane components, or transfer of transcription factors, oncogenes, noncoding RNAs (miRNAs), mRNAs, and infectious particles to recipient cells. Therefore, in cell biology, EVs are considered important signalosomes with regulatory functions.

The relationship between IBD and EVs has received much attention in recent years. Exosomes derived from many cell types, including hucMSCs, Schistosoma japonicum soluble egg antigen (SEA), IL-10treated dendritic cells, myeloid-derived suppressor cells (MDSCs), and bone mesenchymal stem cells (BMSCs), have been shown to attenuate colitis in experimental mice or rats $(32,33,34)$. Thus, exosomes may be a novel and important measure for IBD treatment. This study showed that serum exosomes from Hp-positive patients with chronic gastritis also attenuated DSS-induced colitis in mice. These results provide not only theoretical bases for the search for effective intervention strategies for IBD but also a partial explanation for the mechanisms underlying the protective function of Hp infection in IBD. In addition, we showed that the protective function of Exo( $\mathrm{Hp})$ on colitis in mice was closely associated with NLRP12 expression.

Inflammasomes are mainly composed of recognition, linker, and effector molecules. Recognition molecules include many types of nucleotide-binding oligomerization domain (NOD)-like receptors (NLRs). ASC is a linker molecule that contains a caspase activation and recruitment domain (CARD). Effector molecules include caspase-1 and caspase-11 in the inflammatory caspase family. NLRP12 is a recently discovered NLR that is expressed mainly in bone marrow mononuclear cells, such as macrophages, granulocytes, and immature dendritic cells. In addition, NLRP12 is also expressed in the small intestine, caecum, colon, and mesenteric lymph nodes (35). NLRP12 has many functions, including inflammasome-dependent and inflammasome-independent functions. Currently, NLRP12 is thought to have dual functions in inflammatory responses, including anti-inflammatory and inhibitory functions. 
However, the majority of studies support the hypothesis that NLRP12 has negative regulatory functions with respect to inflammation. Initial studies showed that NLRP12 activated the caspase-1 and NF-KB signaling pathways. NLRP12 binds to ASC to form NLRP12 inflammasomes and activate caspase-1, thus promoting IL-1 $\beta$ release (36). NLRP12 has also been shown to negatively regulate the Toll-like receptormediated expression of inflammatory cytokines $(25,37)$. Some studies have reported that NLRP12 regulates neutrophil functions and inhibits neutrophil migration(38). Functions of NLRP12 specific to colitis have also been reported. In mice with colitis, NLRP12 can reduce the inflammatory responses, the expression of pro-inflammatory cytokines, and the development of colitis-induced tumors. In NLRP12 gene-knockout mice, colitis can be easily induced, the expression of cytokines and chemokines is increased, and the risk of pathological hyperplasia and carcinogenesis in intestinal epithelial cells is increased $(25,26)$. In addition, NLRP12 function was associated with inhibition of the noncanonical NFKB signaling pathway and the MAPK signaling pathway. This study showed that serum exosomes derived from Hp-positive patients with gastritis improved DSS-induced inflammatory responses in mice with colitis and that this function was associated with high NLRP12 expression. Furthermore, the in vitro experiment showed that Exo( $\mathrm{Hp})$ induced an anti-inflammatory function of NLRP12 that was closely associated with the Notch signaling pathway.

The Notch signaling pathway is composed of Notch receptors, Notch ligands, and DNA-binding proteins. There are 4 types of Notch receptors (Notch 1-4) that are extensively distributed in human lymphocytes, vascular endothelial cells, and intestinal epithelial cells. Following ligand binding, the Notch intracellular domain (NICD) in the Notch receptor is released by a metalloproteinase and g-secretase, and it travels to the nucleus where it modulates the expression of a Notch target gene such as Hes-1. Recent studies have shown that the Notch signaling pathway is associated with intestinal inflammatory diseases. Under physiological conditions, activation of the Notch signaling pathway maintains a balanced and coordinated relationship between the promotion of proliferation and the regulation of differentiation of colonic epithelial cells. Moderate activation of the Notch signaling pathway can both effectively promote the renewal of colonic epithelial cells and maintain the balance of normal differentiation between absorptive and secretory cells. Furthermore, the Notch signaling pathway can regulate the balance of the cytokine network through the regulation of $\mathrm{T}$ cell proliferation and differentiation, thus mediating the intestinal immune system (39). During IBD development, this balance is disrupted, and the activation levels and activation regions of the Notch signaling pathway are changed in the colonic mucosa, resulting in the destruction of the intestinal immune balance(40). Our in vitro experiments showed that Exo(Hp)-induced NLRP12 overexpression in intestinal epithelial cells inhibited the Notch signaling pathway to inhibit MCP-1 and MIP-1 a chemokine expression. In the animal model, we also observed that attenuation of DSS-induced colitis by Exo(Hp) was associated with the downregulation of MCP-1 and MIP-1a in intestinal mucosal tissues.

As described above, exosomes are rich in substances from mother cell components, including proteins, lipids, and nucleic acids (mRNAs and noncoding RNAs). Serum exosomes carrying CagA have been shown to enter the blood circulation. Exosomes can be transported to organs and tissues to participate in the pathogenesis of Hp-induced extragastric diseases (13). Our study showed that Exo(Hp) promoted 
NLRP12 expression in intestinal epithelial cells. We do not know whether exosomes carry some pathogenic components of $\mathrm{Hp}$ to stimulate NLRP12 expression in intestinal epithelial cells as antigens or whether exosomes carry some protein and RNA components from mother cells to directly or indirectly regulate NLRP12 expression through signaling pathways. Therefore, proteomics or RNA-omics analyses must be performed to identify the components carried by Exo(Hp).

\section{Conclusions}

This study discovered that serum-derived exosomes from Hp-positive patients with chronic gastritis promoted NLRP12 expression in intestinal epithelial cells and inhibited the Notch signaling pathway to downregulate the expression of the intestinal epithelial chemokines MCP-1 and MIP-1a. In addition, animal experiments indicated that Exo( $\mathrm{Hp})$ attenuated DSS-induced inflammatory responses in mice with colitis and improved colitis symptoms. This function was closely associated with high NLRP12 expression. This study first investigated the intestinal protection mechanisms of Hp infection in IBD from the perspective of exosomes. These results provide novel theoretical bases for further elucidation of the immune regulatory mechanisms of intestinal mucosal injury in IBD and new directions and targets for the exploration of effective interventional strategies for IBD.

\section{Abbreviations}

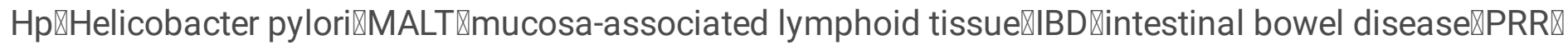

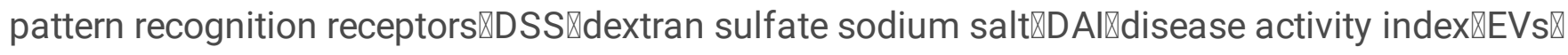
extracellular vesicles $₫$ NLRs $₫$ nucleotide-binding oligomerization domain (NOD)-like receptors. NICD $₫$ Notch intracellular domain. PCDAl: Pediatric Crohn's Disease Activity Index. PUCAI: Pediatric Ulcerative Colitis Activity Index.

\section{Declarations}

\section{Authors'contributions}

CDX and PL conceived the idea and directed the whole project. YFC carried out most of the experiments. $\mathrm{JBH}$ collected the clinical samples. $\mathrm{HL}$ performed the analysis and interpretation of the results.YFC wrote the paper.All authors were involved in editing the manuscript and approved final version of manuscript.

\section{Acknowledgements}

We thank Tong Zhou (Department of Pediatrics, Rui Jin Hospital, 197 Rui Jin Road II, Shanghai 200025, China) for revision of the manuscript prior tosubmission.

\section{Competing interests}

The authors declare no competing financial interests. 
Availability of data and materials

The datasets used and analysed during the current study are available from the corresponding author on reasonable request.

\section{Consent for publication}

Not applicable.

\section{Ethics approval and consent to participate}

This study was approved by the ethics committee of Shanghai Jiao Tong University School of Medicine, and all participants signed informed consent forms prior to specimen collection.

\section{Funding}

This work was supported by National Natural Science Foundation of China $(81570508,81470941$, 81400588, 81741103 and 81372187).

\section{References}

1. Graham DY, Fischbach L. Helicobacter pylori infection. N Engl J Med.2010; 363囚 595-6.

2. Polk DB, Peek RM, Jr. Helicobacter pylori: gastric cancer and beyond. Nat Rev Cancer. 2010;10®40314.

3. Bhandari A, Crowe SE. Helicobacter pylori in gastric malignancies. Curr Gastroenterol Rep.2012; 14: 489-96.

4. Fukase K, Kato M, Kikuchi S, Inoue K, Uemura N, Okamoto S, Terao S, Amagai K, Hayashi S, Asaka M, et al. Effect of eradication of Helicobacter pylori on incidence of metachronous gastric carcinoma after endoscopic resection of early gastric cancer: an open-label, randomised controlled trial. Lancet. 2008;372:392-7.

5. el-Omar E1, Penman I, Cruikshank G, Dover S, Banerjee S, Williams C, McColl KE. Low prevalence of Helicobacter pylori in inflammatory bowel disease: association with sulphasalazine. Gut.1994; 35:1385-8.

6. Franks I. Infection: Helicobacter pylori infection may be protective against IBD. Nat Rev Gastroenterol Hepatol.2011; 8:2.

7. Parente F, Molteni P, Bollani S, Maconi G, Vago L, Duca PG, Rembacken B, Axon AT, Bianchi Porro G.Prevalence of Helicobacter pylori infection and related upper gastrointestinal lesions in patients with inflammatory bowel diseases. A cross-sectional study with matching. Scand J Gastroenterol .1997;32:1140-6.

8. Piodi LP, Bardella M, Rocchia C, Cesana BM, Baldassarri A, Quatrini M.Possible protective effect of 5aminosalicylic acid on Helicobacter pylori infection in patients with inflammatory bowel disease. J 
Clin Gastroenterol.2003; 36:22-5.

9. Smythies LE, Smythies JR. Exosomes in the gut. Front Immunol.2014; 5:104.

10. Hu G, Gong AY, Roth AL, Huang BQ, Ward HD, Zhu G, Larusso NF, Hanson ND, Chen XM. Release of luminal exosomes contributes to TLR4-mediated epithelial antimicrobial defense. PLoS Pathog. 2013; 9: e1003261.

11. Mao F, Wu Y, Tang X, Kang J, Zhang B, Yan Y, Qian H, Zhang X, Xu W.Exosomes derived from human umbilical cord mesenchymal stem cells relieve inflammatory bowel disease in mice. Biomed Res Int.2017; 2017:5356760.

12. Wang J, Deng Z, Wang Z, Wu J, Gu T, Jiang Y, Li G.MicroRNA-155 in exosomes secreted from helicobacter pylori infection macrophages immunomodulates inflammatory response. Am J Transl Res.2016; 8:3700-9.

13. Shimoda A, Ueda K, Nishiumi S, Murata-Kamiya N, Mukai SA, Sawada S, Azuma T, Hatakeyama M, Akiyoshi K.Exosomes as nanocarriers for systemic delivery of the Helicobacter pylori virulence factor CagA. Sci Rep.2016; 6:18346.

14. Hyams J, Markowitz J, Otley A, Rosh J, Mack D, Bousvaros A, Kugathasan S, Pfefferkorn M, Tolia V, Evans $J$, et al. Evaluation of the pediatric crohn disease activity index: a prospective multicenter experience. J Pediatr Gastroenterol Nutr. 2005;41:416-21.

15. Turner D, Hyams J, Markowitz J, Lerer T, Mack DR, Evans J, Pfefferkorn M, Rosh J, Kay M, Crandall W, et al.Appraisal of the pediatric ulcerative colitis activity index (PUCAI). Inflamm Bowel Dis.2009; 15:1218-23.

16. Zhang Y, Liu F, Yuan Y, Jin C, Chang C, Zhu Y, Zhang X, Tian C, He F, Wang J.Inflammasome-derived exosomes activate NF-kappaB signaling in macrophages. J Proteome Res.2017;16:170-8.

17. Soundara Rajan T, Giacoppo S, Diomede F, Bramanti P, Trubiani O, Mazzon E.Human periodontal ligament stem cells secretome from multiple sclerosis patients suppresses NALP3 inflammasome activation in experimental autoimmune encephalomyelitis. Int $\mathrm{J}$ Immunopathol Pharmacol.2017;30:238-52.

18. de Rivero Vaccari JP, Brand F 3rd, Adamczak S, Lee SW, Perez-Barcena J, Wang MY, Bullock MR, Dietrich WD, Keane RW. Exosome-mediated inflammasome signaling after central nervous system injury. J Neurochem.2016; 136:39-48.

19. Ataide MA, Andrade WA, Zamboni DS, Wang D, Souza Mdo C, Franklin BS, Elian S, Martins FS, Pereira D, Reed G, et al. Malaria-induced NLRP12/NLRP3-dependent caspase-1 activation mediates inflammation and hypersensitivity to bacterial superinfection. PLoS Pathog.2014; 10:e1003885.

20. Vladimer GI, Weng D, Paquette SW, Vanaja SK, Rathinam VA, Aune MH, Conlon JE, Burbage JJ, Proulx MK, Liu Q, et al. The NLRP12 inflammasome recognizes Yersinia pestis. Immunity.2012; 37:96-107.

21. Shi F, Yang Y, Kouadir M, Xu W, Hu S, Wang T. Inflammasome-independent role of NLRP12 in suppressing colonic inflammation regulated by Blimp-1. Oncotarget .2016;7:30575-84. 
22. Radtke F, Wilson A, MacDonald HR. Notch signaling in T- and B-cell development. Curr Opin Immunol.2004; 16:174-9.

23. Xie H, Sun J, Chen Y, Zong M, Li S, Wang Y. EGCG Attenuates Uric Acid-Induced Inflammatory and Oxidative Stress Responses by Medicating the NOTCH Pathway. Oxid Med Cell Longev.2015; 2015:214836.

24. Qi J, Yang Y, Hou S, Qiao Y, Wang Q, Yu H, Zhang Q, Cai T, Kijlstra A, Yang P. Increased Notch pathway activation in Behcet's disease. Rheumatology (Oxford).2014; 53:810-20.

25. Zaki MH, Vogel P, Malireddi RK, Body-Malapel M, Anand PK, Bertin J, Green DR, Lamkanfi M, Kanneganti TD. The NOD-like receptor NLRP12 attenuates colon inflammation and tumorigenesis. Cancer cell.2011; 20:649-60.

26. Allen IC, Wilson JE, Schneider M, Lich JD, Roberts RA, Arthur JC, Woodford RM, Davis BK, Uronis JM, Herfarth $\mathrm{HH}$, et al. NLRP12 suppresses colon inflammation and tumorigenesis through the negative regulation of noncanonical NF-kappaB signaling. Immunity.2012; 36:742-54.

27. Turturici G, Tinnirello R, Sconzo G, Geraci F. Extracellular membrane vesicles as a mechanism of cellto-cell communication: advantages and disadvantages. Am J Physiol Cell Physiol.2014; 306:C62133.

28. Beach A, Zhang HG, Ratajczak MZ, Kakar SS. Exosomes: an overview of biogenesis, composition and role in ovarian cancer. J Ovarian Res.2014; 7:14.

29. Kowal J, Tkach M, Thery C. Biogenesis and secretion of exosomes. Curr Opin Cell Biol.2014; 29:11625.

30. Raposo G, Nijman HW, Stoorvogel W, Liejendekker R, Harding CV, Melief CJ, Geuze HJ. B lymphocytes secrete antigen-presenting vesicles. J Exp Med.1996; 183:1161-72.

31. Lee Y, El Andaloussi S, Wood MJ. Exosomes and microvesicles: extracellular vesicles for genetic information transfer and gene therapy. Hum Mol Genet .2012;21:R125-34.

32. Wang L, Yu Z, Wan S, Wu F, Chen W, Zhang B, Lin D, Liu J, Xie H, Sun X, et al. Exosomes Derived from Dendritic Cells Treated with Schistosoma japonicum Soluble Egg Antigen Attenuate DSS-Induced Colitis. Front Pharmacol.2017; 8:651.

33. Wang Y, Tian J, Tang X, Rui K, Tian X, Ma J, Ma B, Xu H, Lu L, Wang S. Exosomes released by granulocytic myeloid-derived suppressor cells attenuate DSS-induced colitis in mice. Oncotarget.2016; 7:15356-68.

34. Yang J, Liu XX, Fan H, Tang Q, Shou ZX, Zuo DM, Zou Z, Xu M, Chen QY, Peng Y, et al. Extracellular Vesicles Derived from Bone Marrow Mesenchymal Stem Cells Protect against Experimental Colitis via Attenuating Colon Inflammation, Oxidative Stress and Apoptosis. PloS one.2015; 10:e0140551.

35. Chen GY. Role of Nlrp6 and Nlrp12 in the maintenance of intestinal homeostasis. Eur J Immunol.2014; 44:321-7.

36. Wang L, Manji GA, Grenier JM, Al-Garawi A, Merriam S, Lora JM, Geddes BJ, Briskin M, DiStefano PS, Bertin J. PYPAF7, a novel PYRIN-containing Apaf1-like protein that regulates activation of NF-kappa B and caspase-1-dependent cytokine processing. J Biol Chem.2002; 277:29874-80. 
37. Zaki MH, Man SM, Vogel P, Lamkanfi M, Kanneganti TD. Salmonella exploits NLRP12-dependent innate immune signaling to suppress host defenses during infection. Proc Natl Acad Sci U S A.2014; 111:385-90.

38. Zamoshnikova A, Groß CJ, Schuster S, Chen KW, Wilson A, Tacchini-Cottier F, Schroder K. NLRP12 is a neutrophil-specific, negative regulator of in vitro cell migration but does not modulate LPS- or infection-induced NF-kappaB or ERK signalling. Immunobiology.2016; 221:341-6.

39. Vooijs M, Liu Z, Kopan R. Notch: architect, landscaper, and guardian of the intestine. Gastroenterology.2011; 141:448-59.

40. Werner L, Berndt U, Paclik D, Danese S, Schirbel A, Sturm A. TNFalpha inhibitors restrict T cell activation and cycling via Notch-1 signalling in inflammatory bowel disease. Gut.2012; 61:1016-27.

\section{Tables}

Table 1 Characteristics of the gastritis patients and healthy volunteers selected for serum exosomes extraction

\begin{tabular}{|c|c|c|c|c|c|c|c|c|}
\hline & No. & $\begin{array}{c}\text { Age } \\
\text { (years) }\end{array}$ & Gender & $\overline{\mathrm{BMI}}$ & $\begin{array}{l}\text { Dyspeptic } \\
\text { symptoms }\end{array}$ & $\begin{array}{l}\text { Chronic } \\
\text { gastritis }\end{array}$ & $\begin{array}{c}{ }^{13} \mathrm{C} \text { breath } \\
\text { tests }\end{array}$ & $\begin{array}{l}\text { H. pylori } \\
\text { infection }\end{array}$ \\
\hline & $\overline{1}$ & $\overline{6}$ & $\bar{F}$ & 14.7 & Yes & Severe & + & + \\
\hline Gastritis & 2 & 7 & M & 17.2 & Yes & Severe & + & + \\
\hline \multirow[t]{3}{*}{ patients } & 3 & 6 & $\mathrm{~F}$ & 15.1 & Yes & Severe & + & + \\
\hline & 4 & 7 & M & 16.2 & Yes & Severe & + & + \\
\hline & 5 & 8 & M & 15.7 & Yes & Severe & + & + \\
\hline Healthy & 1 & 6 & M & 16.6 & No & No & - & - \\
\hline \multirow[t]{2}{*}{ volunteers } & 2 & 7 & $\mathrm{~F}$ & 14.9 & No & No & - & - \\
\hline & 3 & 7 & M & 16.5 & No & No & - & - \\
\hline
\end{tabular}

M, male; F, female.BMI, Body Mass Index;+, Positive;-, Negative.

Table 2.The primers sequence used for Real time PCR

\begin{tabular}{|c|c|c|c|}
\hline Gene & Species & Forward primer $05^{\prime}-3^{\prime} \square$ & Reverse primer[5'-3'] \\
\hline$\overline{\mathrm{AM}-1}$ & Human & GCAAGAAGATAGCCAACCA & TGCCAGTTCCACCCGTTC \\
\hline$-1 \alpha$ & Human & GGCAACACCATTGAAGGC & CGGGAGGTATGCGTAAGG \\
\hline-2 & Human & GCATTTACTGCTGGATTT & ATGTTTCAGTTCTGTGGC \\
\hline-4 & Human & GCAGTTCCACAGGCACAA & TGGTTGGCTTCCTTCACA \\
\hline$-6 \mathrm{R}$ & Human & GTGGTCTATGGGTTTGTTTC & CACCTGGGTTAGCCTTCT \\
\hline GF-BB & Human & GAGGTGGCTGTAGATGGTGA & TGGTGGAGCAGACTGAAGG \\
\hline INTES & Human & CCCTCGCTGTCATCCTCA & GCACTTGCCACTGGTGTAG \\
\hline$J F-\alpha$ & Human & CGAGTCTGGGCAGGTCTA & GTGGTGGTCTTGTTGCTTAA \\
\hline CP-1 & Human & AGAATCACCAGCAGCAAG & GGAATCCTGAACCCACTT \\
\hline$[\mathrm{P}-1 \alpha$ & Human & GCCCTTGCTGTCCTCCTCT & CACTGGCTGCTCGTCTCA \\
\hline $\operatorname{tch} 1$ & Human & ATGTTGGAGAAGGGAAGTTGAA & GCAGGTGATGCTGGTGGA \\
\hline gged1 & Human & CAACGGCGAGTCCTTTAC & CTGGCATTCATTGATGTTTA \\
\hline s- 1 & Human & AGCTCGCGGCATTCCAAG & AGCGGGTCACCTCGTTCA \\
\hline s5 & Human & CACAGCAAAGCCTTCGTCG & GTGGAGCGTCAGGAACTGC \\
\hline ¿RP12 & Mouse & GACCGCAATGCACGATTA & TGGTGACGCCTGGTTCTG \\
\hline CP-1 & Mouse & САСААССАССТСААGСАС & AAGGGAATACCATAACATCA \\
\hline$[\mathrm{P}-1 \alpha$ & Mouse & ACTGACCTGGAACTGAATG & GAAGAGTCCCTCGATGTG \\
\hline$J F-\alpha$ & Mouse & СССТСАСАСТСAGATCATCTTСТ & GCTACGACGTGGGCTACAG \\
\hline$N-\gamma$ & Mouse & GGAACTGGCAAAAGGATGGTGAC & GCTGGACCTGTGGGTTGTTGAC \\
\hline$-1 \dot{\beta}$ & Mouse & AGCTTCAGGCAGGCAGTATC & TCATCTCGGAGCCTGTAGTG \\
\hline-10 & Mouse & CCTGGCTCAGCACTGCTATG & TCACCTGGCTGAAGGCAGTC \\
\hline $\mathrm{APDH}$ & Human & TTCACCACCATGGAGAAGGC & САСАСССАТСАСАААСАTGGG \\
\hline$\triangle \mathrm{PDH}$ & Mouse & TGTTTCCTCGTCCCGTAG & CAATCTCСАCTTTGCCACT \\
\hline
\end{tabular}


Table3. Inflammasome-related genes regulated by serum exosomes derived from Helicobacter pylori-positive patients

\begin{tabular}{|c|c|c|c|c|}
\hline Symbol & Description & RefSeq & $\begin{array}{c}\text { Fold } \\
\text { Change,Hp/Con }\end{array}$ & p-value \\
\hline AIM2 & absent in melanoma 2 & NM 004833 & 1.32 & NS \\
\hline NAIP & NLR family apoptosis inhibitory protein & NM_001346870 & 1.99 & $*$ \\
\hline NLRC4 & NLR family CARD domain containing 4 & NM 001199138 & 0.72 & NS \\
\hline NLRC5 & NLR family CARD domain containing 5 & NM_032206 & 0.87 & NS \\
\hline NLRP1 & NLR family pyrin domain containing 1 & NM 033004 & 0.68 & NS \\
\hline NLRP12 & NLR family pyrin domain containing 12 & NM_001277126 & 5.34 & *** \\
\hline NLRP3 & NLR family pyrin domain containing 3 & NM_001079821 & 0.45 & $*$ \\
\hline NLRP4 & NLR family pyrin domain containing 4 & NM_134444 & 0.94 & NS \\
\hline NLRP5 & NLR family pyrin domain containing 5 & $\mathrm{NM}^{-} 153447$ & 0.42 & * \\
\hline NLRP6 & NLR family pyrin domain containing 6 & NM_138329 & 0.71 & NS \\
\hline NLRP9 & NLR family pyrin domain containing 9 & NM_176820 & 1.25 & NS \\
\hline NOD1 & nucleotide binding oligomerization domain containing & NM 006092 & 1.28 & NS \\
\hline & nucleotide binding oligomerization domain containing & & 0.52 & \\
\hline NOD2 & 2 & NM_022162 & & NS \\
\hline CIITA & $\begin{array}{c}\text { class II major histocompatibility complex } \\
\text { transactivator }\end{array}$ & NM 000246 & 0.43 & NS \\
\hline NLRX1 & NLR family member X1 & NM 024618 & 0.99 & NS \\
\hline
\end{tabular}

$* P<0.05,{ }^{* * *} P<0.001$, NS: not significant. 
a

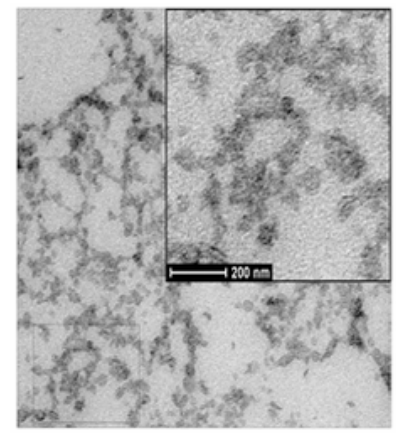

b

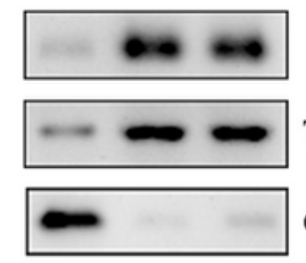

NCM460 Exo(Con) $\operatorname{Exo}(\mathrm{Hp})$

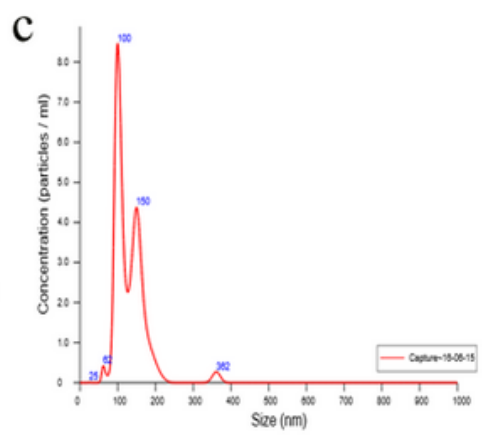

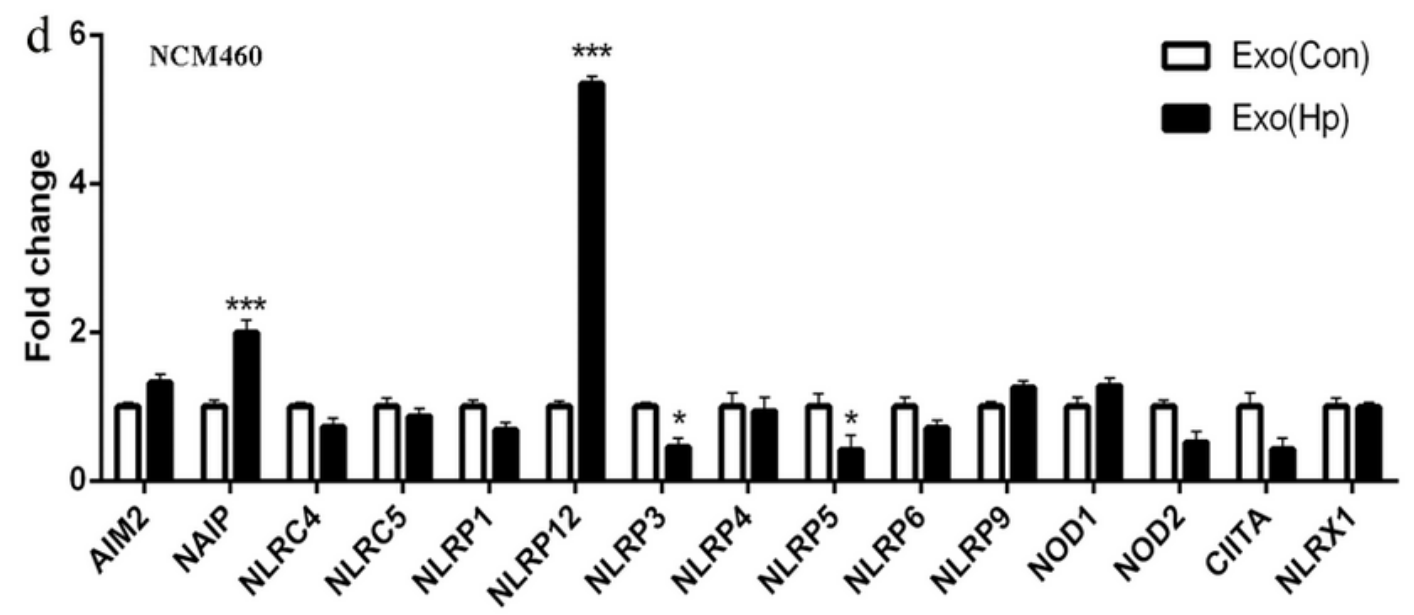
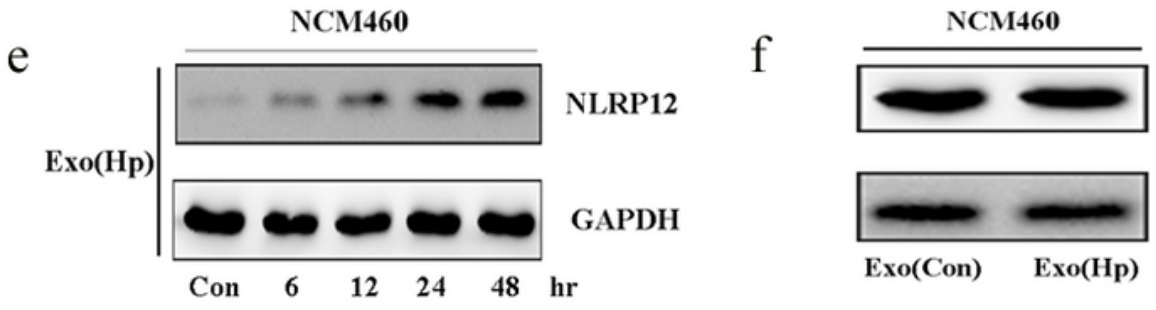

NLRP3
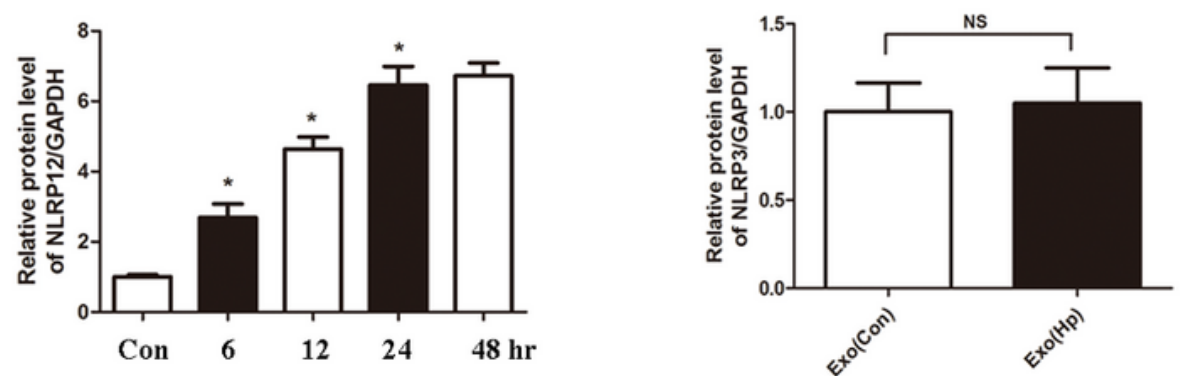

Figure 1

Identification of inflammasomes expression in NCM460 cells regulated by Exo( $\mathrm{Hp})$. a:Electron micrograph of ExoهHp囚revealing the typical morphology and size (50-140 nm). b:CD63, TSG101 and calnexin expression in exosomes were assessed by Western blotting. Exo(Con): exosomes isolated from serum of healthy volunteers; Exo(Hp): exosomes isolated from serum of Hp positive patients. c: The nanoparticle tracking analysis of the exosome preparations was performed by using a Nanosight system, 
and a peak was observed at approximately $100 \mathrm{~nm} . \mathrm{d}$ : NCM460 were stimulated by the extracted exosomes $(100 \mu \mathrm{g} / \mathrm{mL})$ for $24 \mathrm{~h}$, inflammasome-related genes were detected by using PCR array. * $\mathrm{P}<$ $0.05,{ }^{\star} \star \star \mathrm{P}<0.001$.e and f:The NLRP12 and NLRP3 protein level was detected using western blotting. $* \mathrm{P}<$ 0.05 , NS: not significant.

a

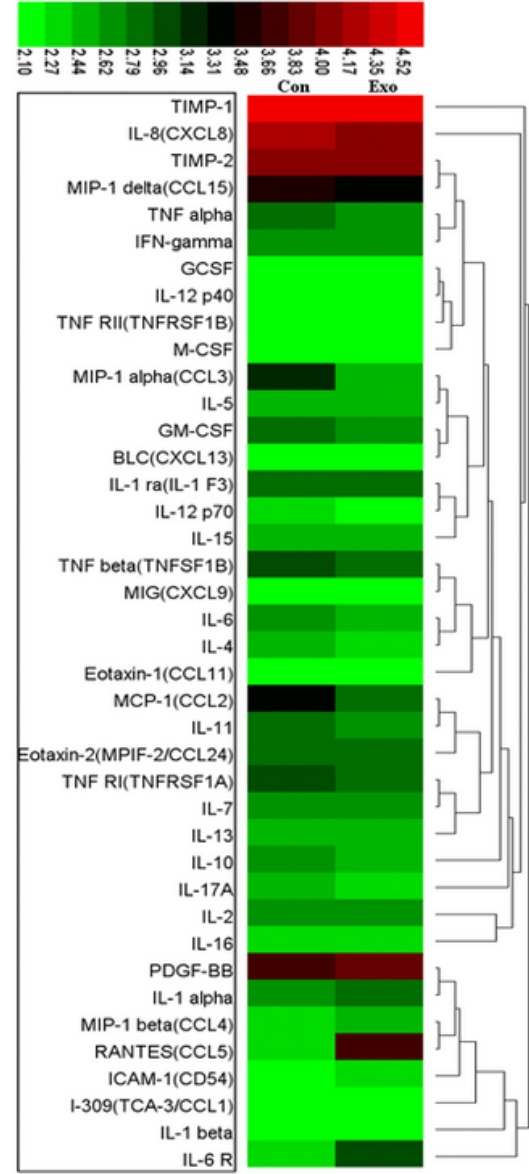

b
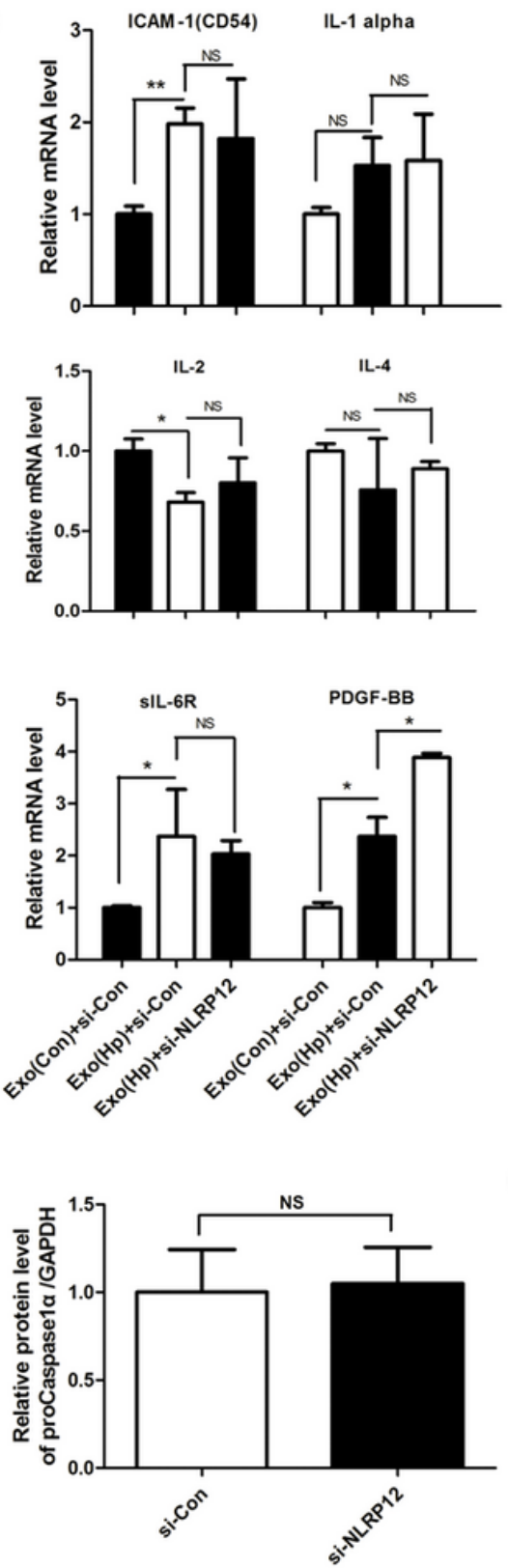
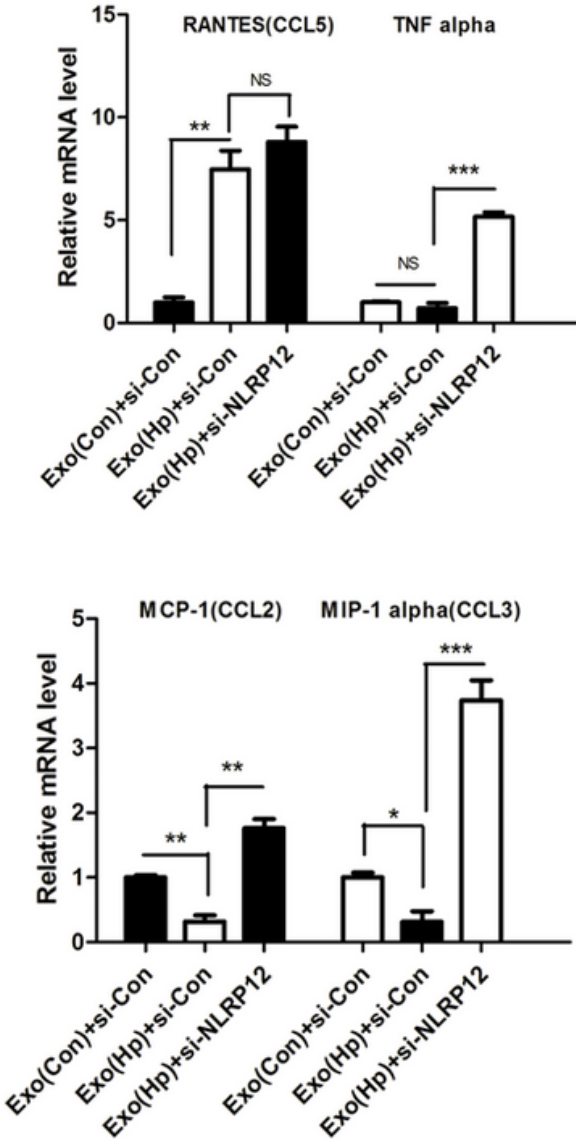

$\mathrm{d}$

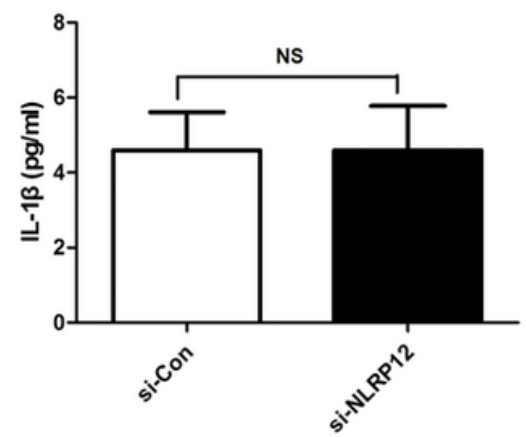

GAPDH

\section{Figure 2}

Exo(Hp)-induced NLRP12 expression inhibit MCP-1 and MIP-1a expression in intestinal epithelial cells. a:NCM460 cells were treated with Exo(Hp) $(100 \mu \mathrm{g} / \mathrm{mL})$ for $24 \mathrm{~h}$, and the cell supernatant was collected for the inflammatory cytokine antibody array. Bound cytokines were recognized by a pool of anti-cytokine antibodies corresponding to the antibodies spotted on the array. Semiquantitative levels are represented in the heat map.Con: exosomes isolated from serum of healthy volunteers; Exo:exosomes isolated from serum of Hp positive patients. b:Interference with NLRP12 expression was performed using siRNA 
technology, and mRNA levels of the above inflammatory cytokines in NCM460 treated with Exo and/or

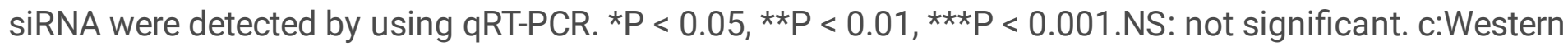
blotting was performed to detect proCaspase-1 protein level in NCM460 treated with NLRP12-siRNA for $24 \mathrm{~h}$. $\mathrm{d}$ :The levels of secreted IL-1 $\beta$ were determined using enzyme-linked immunosorbent assay (ELISA) in NCM460 after knockdown of NLRP12. NS: not significant.

国

\section{Figure 3}

Detection of signaling pathways influenced by $\operatorname{Exo}(\mathrm{Hp})$ through PCR array. a: The expression of the signaling pathway-associated genes in NCM460 was performed by real-time PCR based array analysis. Semiquantitative levels(Fold change in Exo(Hp) group against Exo(Con)group) of differential expression genes in 10 signal transduction were represented in the heat map. b: Expression change of Notch1 protein was detected using western blotting. NICD: Notch1 intracellular domain. ${ }^{\star} P<0.05,{ }^{\star} * P<0.01$, ${ }^{\star \star *} P$ $<0.001$.
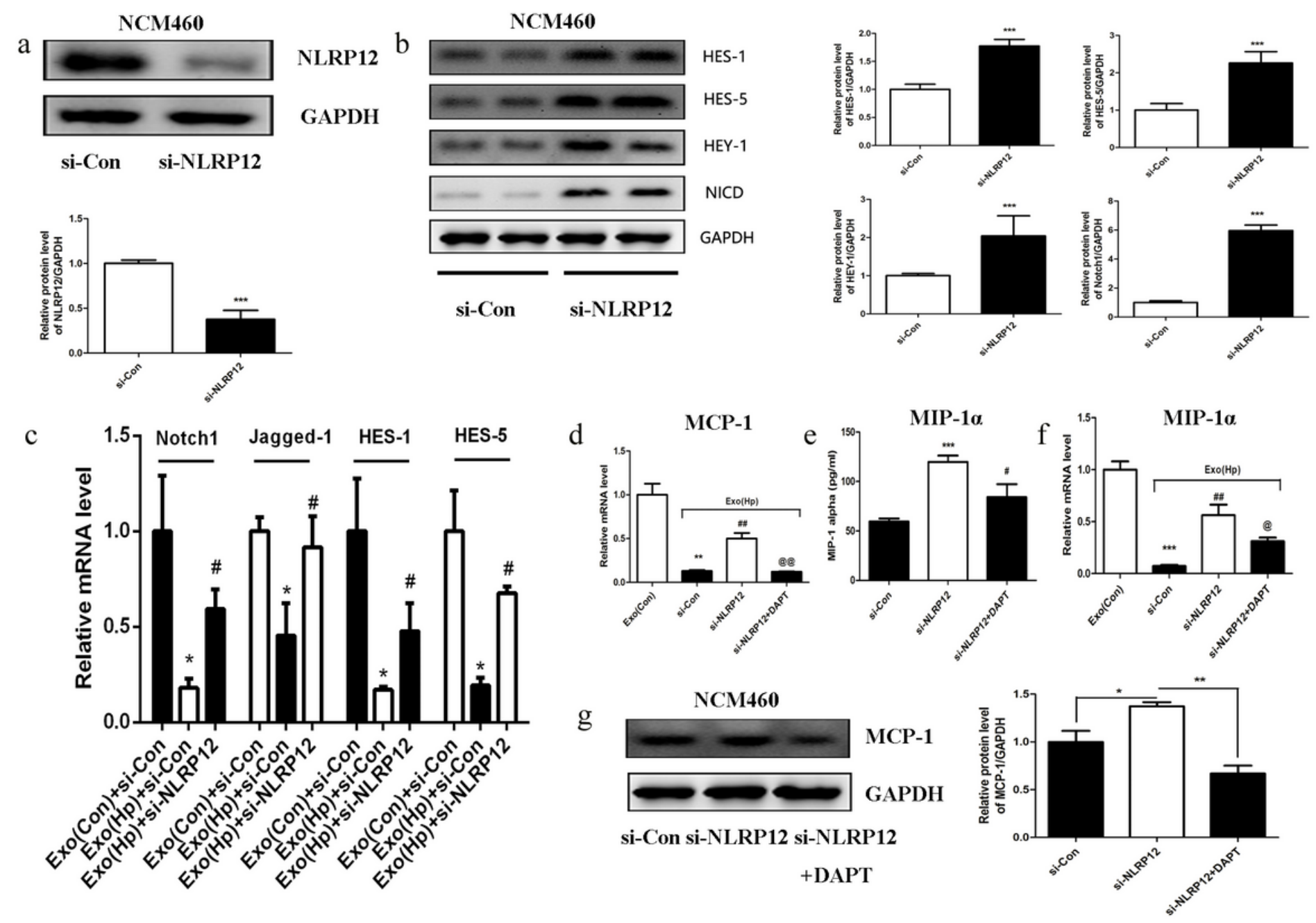

Figure 4 
NLRP12 reduce MCP-1 and MIP-1a expression through inhibition of the Notch signaling pathway. a】 Knockdown efficiency of NLRP12 by siRNA was determined by Western blot and real-time PCR analysis.

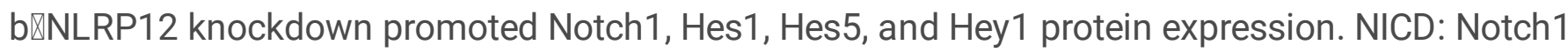

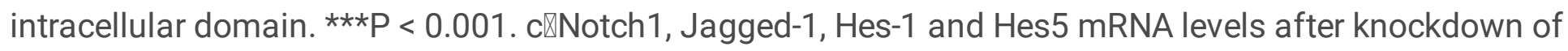
NLRP12 were detected by qRT-PCR. Data represent averages of more than three independent experiments. $* \mathrm{P}<0.05$ :Exo(Hp) group vs Exo(Con)group; $\# \mathrm{P}<0.05$ :si-NLRP12 group vs si-Con group. $\mathrm{d} \mathbb{\mathrm { M }} \mathrm{MCP}-1 \mathrm{mRNA}$ level after NLRP12 knockdown with or without DAPT(the Notch signaling pathway inhibitor) treatment were detected by qRT-PCR. **P<0.01:si-Con vs Exo(Con) group; \# \#P<0.01: si-NLRP12 vs si-Con group;@@ $P<0.01$ : si-NLRP12+DAPT vs si-NLRP12 group. eखMIP-1a secretion influenced by NLRP12 through ELISA analysis. ${ }^{* *} \mathrm{P}<0.001$ : si-NLRP12 vs si-Con group; $\# \mathrm{P}<0.05$ : si-NLRP12+DAPT vs si-NLRP12 group. f $\llbracket \mathrm{MIP}-$ 1a mRNA level after NLRP12 knockdown were observed by qRT-PCR. ${ }^{\star \star *} P<0.001$ :si-Con vs Exo(Con) group; \#\#P<0.01: si-NLRP12 vs si-Con group;@P<0.05: si-NLRP12+DAPT vs si-NLRP12 group. g区MCP-1 protein level was detected using western blotting. ${ }^{*} P<0.05,{ }^{\star *} P<0.01$. 

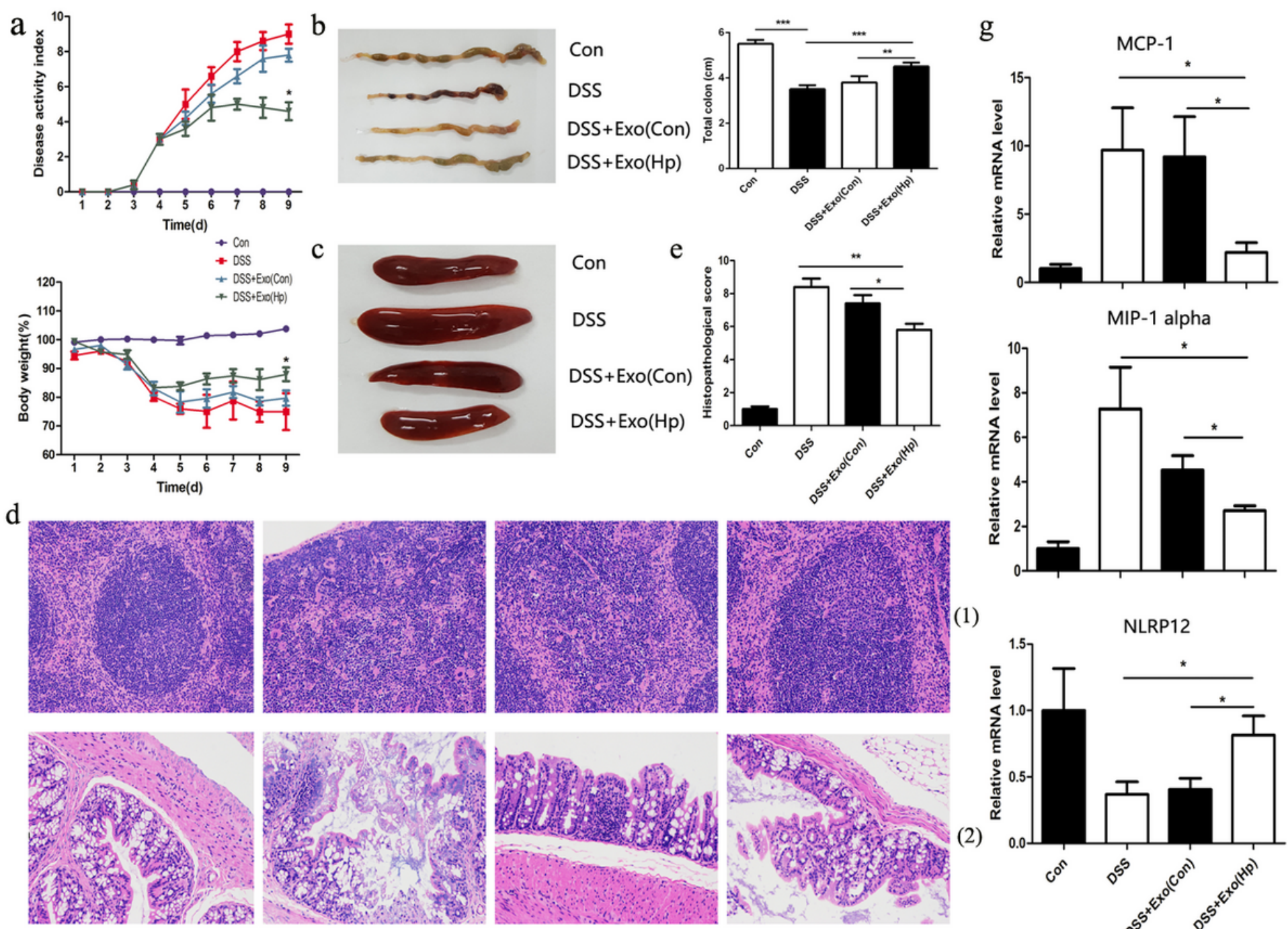

Con

f
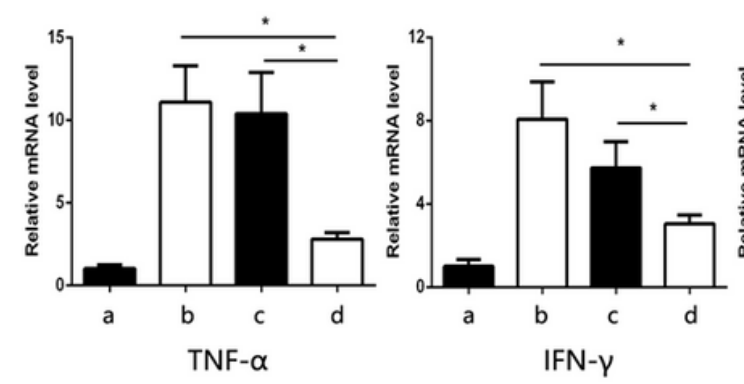

DSS

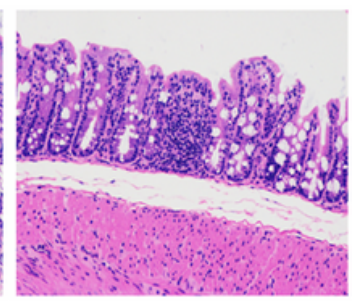

DSS+Exo(Con)
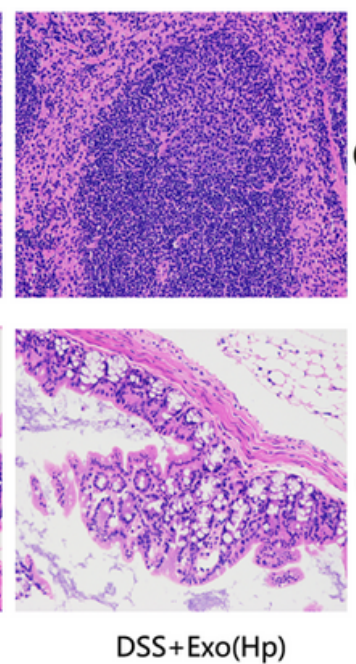

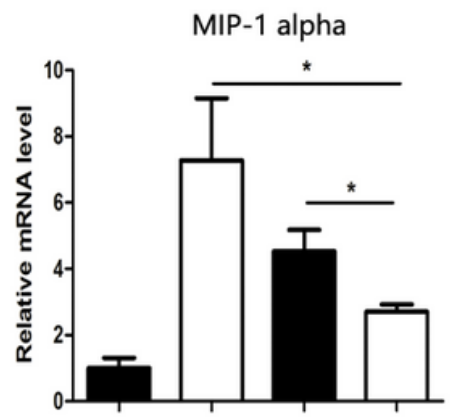

(1)

(2)

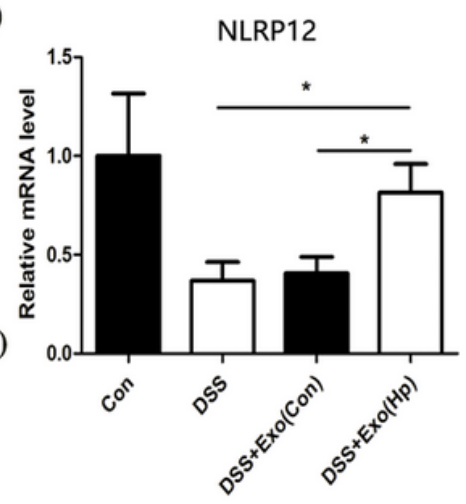

Figure 5

Attenuation of DSS-induced colitis in mice by Exo(Hp). a囚The effect of Exo(Hp) on the disease activity index and body weight of mice $(50 \mu \mathrm{g} /$ mouse).Mice were weighed daily. DAl(disease activity index) was evaluated using the parameters of weight loss, diarrhea, and bleeding. Con: normal control group; DSS: colitis model group received a 5\% DSS solution for drinking. DSS+Exo(Con): 5\% DSS drinking with intraperitoneal injection of exosomes derived from healthy volunteers. DSS+Exo(Hp): $5 \%$ DSS drinking with intraperitoneal injection of exosomes derived from Hp-positive pediatric gastritis patients. ${ }^{*} \mathrm{P}<0.05$ :DSS+Exo(Hp) vs DSS+Exo(Con). b冈The colon lengths of mice in control, DSS, DSS + 
Exo(Con) and DSS+Exo(Hp) groups. ${ }^{* \star P}<0.01,{ }^{* \star *} \mathrm{P}<0.001 . c \otimes T$ The size of the spleens in DSS-induced colitis mice with exosomes treatment. d $\mathbb{V H E}$ staining of the spleens and colon tissues in mice( Control, DSS, DSS + Exo(Con) and DSS + Exo(Hp) groups).(1): spleens;(2): colon tissues. Original magnification: $\times 200$. e区Histologic scoring in DSS-induced colitis mice. ${ }^{*} \mathrm{P}<0.05,{ }^{\star *} \mathrm{P}<0.01$. f: The detection of TNF- $\mathrm{a}$, IFN- $y$, IL$1 \beta$ and IL-10 mRNA expression by qRT-PCR analysis. Quantitation of fecal LCN-2 by ELISA. a:Con,b:DSS,c: DSS + Exo(Con),d: DSS + Exo(Hp). ${ }^{*}<<0.05,{ }^{*} P<0.01$. g®RNA from the mouse colon in all groups were extracted for the detection of MCP-1, MIP-1a and NLRP12 mRNA expression by qRT-PCR analysis. ${ }^{*} \mathrm{P}<0.05$.

$\mathrm{a}$
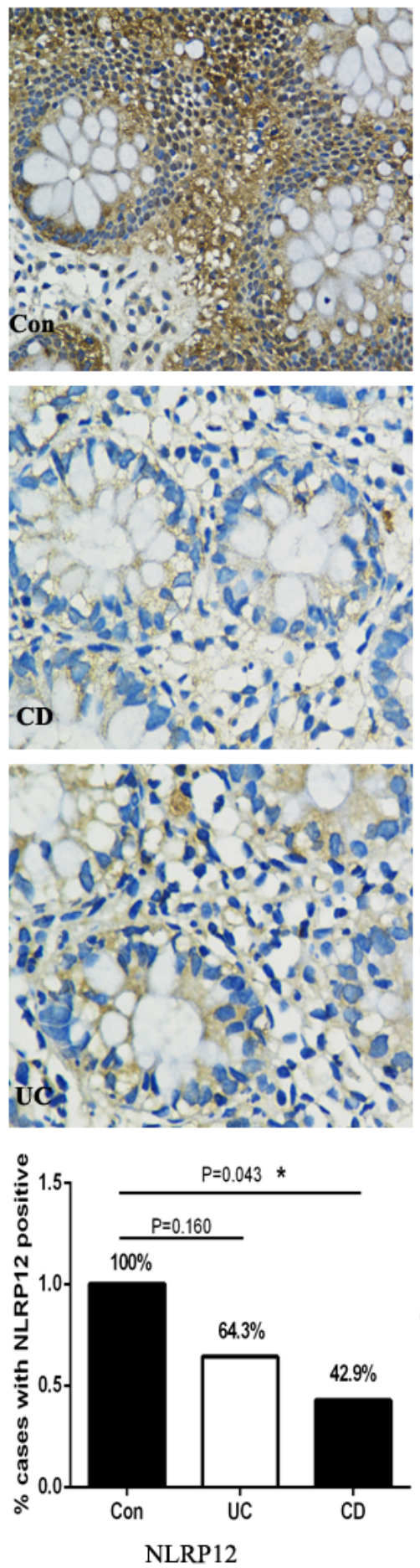

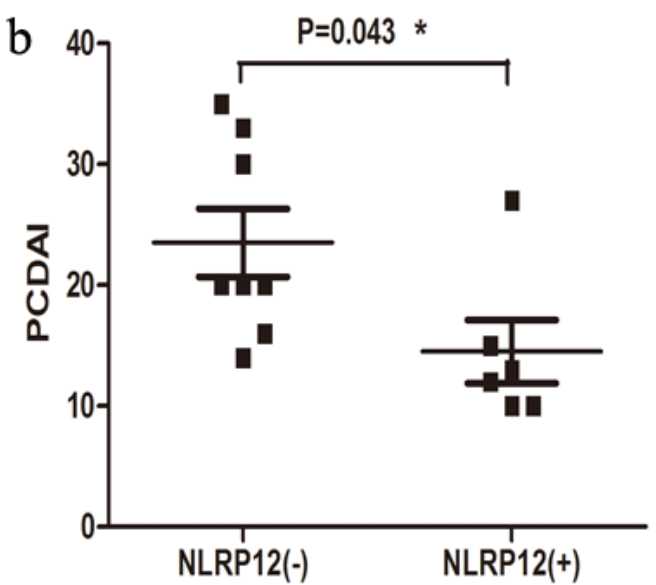

(1)

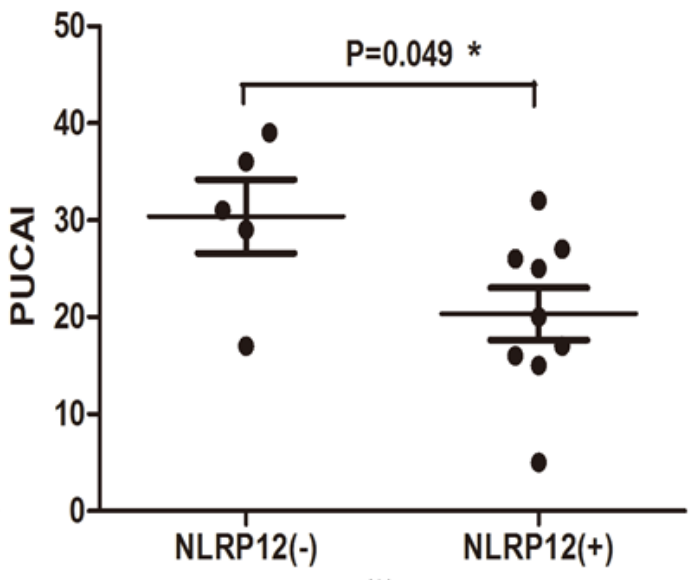

(2)

(2) $\mathrm{C}$

(3)

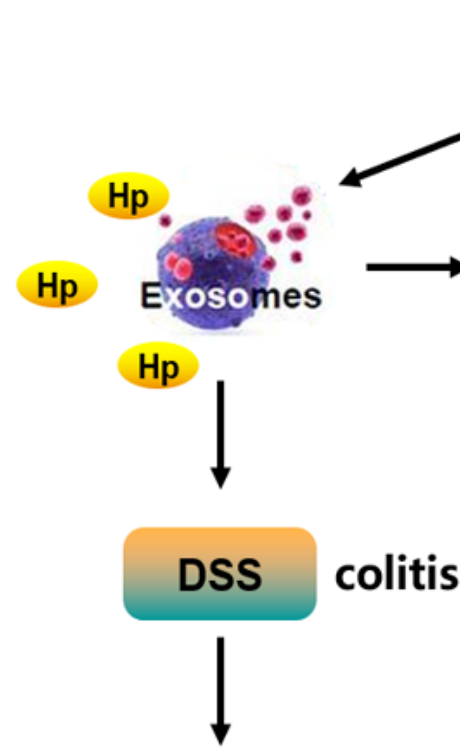

H. pylori
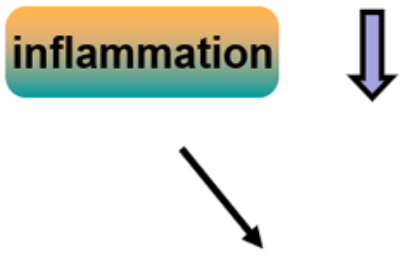

Intestinal epithelial cells
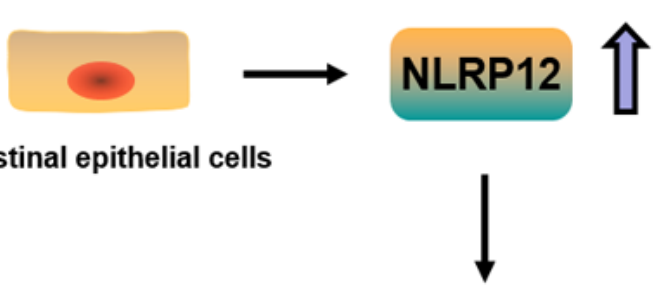

(4)

Protective

IBD

Figure 6 
The correlation between NLRP12 expression and disease activity in pediatric IBD patients.a区 Immunohistochemical staining of NLRP12 in intestinal mucosal tissues of normal controls and IBD patients. Original magnification, $\times 200$. (1)Con: normal controls;(2)CD:Crohn's disease;(3)UC: ulcerative

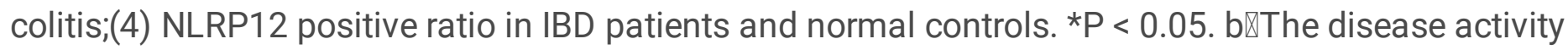
index of the pediatric IBD patients with or without NLRP12 positive expression.PCDAl: Pediatric Crohn's Disease Activity Index;PUCAI: Pediatric Ulcerative Colitis Activity Index. ${ }^{*} P<0.05$.c: Hypothetical schematic of the role of Exo(Hp) in immune regulatory mechanisms in IBD. 